\section{WHAT ARE DISEASES?}

\author{
By C. HANDFIELD JONES, M.B., F.R.C.P., F.R.S., \\ Physician and co-Lecturer on Medicine at St. Mary's Hospital.
}

WhAT are Diseases? It might seem easy to answer the question by a simple reference to the list furnished us by the Registrar-General. On inspecting this, however, we soon become aware that often one name covers a number of very diverse conditions (as, for instance, metria, dyspepsia, nephria, cephalœa, vertigo); and, besides this, often a name merely implies the presence of some prominent symptom, which may exist equally marked in several different states, e. $g$., paralysis, icterus, hæmaturia. It is quite evident that the terms which figure in nosologies are really little more than convenient façons de parler, and can claim very little scientific precision. Such terms we must have, but then we must be very careful that we do not imagine them to possess an accuracy which really does not belong to them.

If we ask the above question of each other as men whose serious business is the relief or cure of suffering, we want other information than can be afforded us by a set of names. We want to know whether the signs of distress and disorder which arrest our attention, or which we discover on search, can be trusted to direct our minds into such an intelligent comprehension of the morbid process going on as shall enable us to take the best measures practicable for its relief. We want to know whether similarity of phenomena perceptible to the senses implies necessarily similarity of productive action. These queries are put not in any spirit of curious speculation; they lie at the very root of all attempts to give real accuracy to the diagnosis and treatment of disease. That surely cannot be esteemed a sufficient diagnosis which concerns itself only with the surface-phenomena, and omits altogether to take account of the more recondite, but more essential particulars. It does not require a conjuror to diagnose bronchitis, but it may demand some careful inquiry to ascertain the quality of the bronchitis, whether sthenic, or asthenic, whether gouty, syphilitic, neurotic (Trousseau), or simple; and on the determination of these, and such like points, the (to my patient) all important question of treatment depends. So with regard to many other classical diseases. Anxious as I have been, and am still, to have inquiries instituted to ascertain the best methods of employing remedies for the relief and removal of sickness, I cannot but see that, unless it be determined beforehand with something like accuracy what are the particular conditions in which a given remedy is to be administered, the conclusions arrived at will not be available for the guidance of others. The chemist can direct a solution of a certain substance to be taken and treated in a certain way, and can assure experimenters confidently that if they observe his directions certain results will invariably follow. But no physician can guarantee to another that he will obtain the same results as he has himself if he follows the same procedure in dealing with an apparently quite similar disease. Even conceding that the morbific causes are identical, it is almost a matter of certainty that the recipient systems are not. Two solutions of the same salt can easily be made exactly and completely the same; where shall we find two human bodies so precisely the pattern of each other? This is the great obstacle to medicine ever becoming an exact science.

Of course I do not mean to deny that, in a great many instances, satisfactory directions can be given for dealing with various forms of morbid action, especially in the same localities and periods of time; but I do wish to protest against the notion, always too easily admitted, that it can be right to speak of the treatment of a disease defined by a mere name and no more.

Let me illustrate what I have advanced by appealing to clinical experience. Erysipelas is a disease most easy of recognition; it is defined in the nomenclature adopted by the College of Physicians as an inflammation of the integument tending to spread indefinitely. Will it be sufficient for a therapeutical committee to proceed with no other datum than this to consider what remedies ought to be administered? I believe not. Various particulars have to be raken into account, which all experienced practitioners have regard to : as the state of the nervous system, and of the circulation, the constitution, general health, habits, residence, and possible idiosyncrasy of the patient, as well as the character of the epidemic, should there be any. While, in the wards of St. Mary's, I have been treating my erysipelatous patients with brandy and bark and ammonia, intelligent house-surgeons have told me that their fathers practising in rural districts found it necessary to bleed or purge their patients before giving them any tonics. Sir Thomas Watson writes: "I really believe that in the purer air of the country, and in young, strong, vigorous country persons, bleeding may be proper and requisite. You will find country practitioners pretty well agreed on this point." Graves's testimony is very decided. "Erysipelas should not be treated from its name-it is a disease capable of exhibiting a great variety of forms, amenable to no fixed line of treatment." He has seen many instances in which erysipelas appeared in a distinct and wellmarked inflammatory form, and has found venesection, leeching, purgatives and tartar emetic, admirably well fitted to remove the disease. But in others wine, opium, and sulphate of quinine, were the only remedies which could be relied on, and no one in his senses would think of using general or local depletion, purgatives, or tartar emetic $(v, 575)$. Dr. Copland writes quite to the same effect. The disease may require "from the very commencement most varied and even opposite modes of cure;" and "frequently also demands an almost equal diversity at different stages of its progress." Where tonics are evidently advisable, it is by no means a settled matter whether the free administration of tincture of perchloride of iron is more desirable, or bark and ammonia. The latter remedies seem to me most appropriate to states of great prostration with marked tendency to death by asthenia, the former to those where there is more reaction and vital tone. Clearly both are not equally proper in the same cases.

Acute rheumatism is another disease most facile of diagnosis. Is it sufficient to name the disease to know its treatment in each case, even with the aid of a definition? Most emphatically I demur to the affirmative. I have no sort of doubt that different cases do require very different kinds of treatment. Quinine is beneficial in some, alkalies in others. The same is true of gout. Dr. Garrod writes : "Although a plan can be sketched out which is applicable to the majority of cases of gout, still each individual case not only exhibits its own peculiarities, and becomes a separate study, but likewise demands, in certain respects, a separate treatment. The neglect of this consideration is apt to lead to a mere routine practice, closely bordering on empiricism." Dr. Gairdner writes in the same strain : "When the minute features of gout are examined, they are found as various as the individuals whom it assails. Again, when called to see a case of gout, three great considerations must take precedence of all others - the age of the patient, his constitution, and the period of the disease. These important circumstances control all our treatment. To use remedies in the indiscriminate manner recommended by Sutton and others cannot fail to expose us, sooner or later, to sad accidents and reverses."

Eczema, again - acute eczema-is very easily named; but, when this is done, we have not thereby attained certainly to know the correct treatment ; cases outwardly alike may need to be dealt with very differently, salines and aperients curing one, full doses of arsenic another. The same may be said of psoriasis. Dysentery presents no difficulty in diagnosis, but convinced, as I am, of the value of the ipecacuan treatment in many cases, I am not ignorant that in China the free use of mercury has proved more successful, nor that Trousseau affirms, as the result of his experience, that "plus spécialement les sels neutres administrés à dose purgative . . . . est donc la méthode curative par excellence de la dysenterie." I cannot think it a matter of indifference whether the dysentery be of the bilious, inflammatory, hæmorrhagic, or rheumatismal kind. Sir R. Martin says "that the most cursory view of the special pathology and associations of dysentery ought to satisfy the medical officer that no one exclusive mode of treating a disease so complicated in its nature can be rational in itself, or successful in its results." $\mathrm{He}$ quotes Sir James McGrigor's statement, " that he became convinced in Alexandria that, with change of country and climate, we had a different disease. This is one proof how improper and unsafe it is for the practitioner of one climate to set down and describe the diseases of another. .... In many of the symptoms diseases may agree, but from thence to infer their identity, is taking a very narrow view." Croup, I more than suspect, requires a different management in rural and urban districts. In the latter bleeding, except by a leech or two, is rarely advisable, and calomel ought, I think, scarcely to be given unless in peculiar instances; in the former, there seems much evidence that both may be used with very good effect. Dr. Cotton's experience in the treatment of phthisis with different drugs leads him to anticipate that it will be shown that under certain, at present, obscure conditions of the system, phthisis assumes definite and special forms, each of which requires definite and special management. With regard to delirium tremens, I feel well assured that no general agreement will ever be come to respecting its treatment, so long as we make no distinction between the very various conditions to which the term is applied. Full opiates, frequent dosing with tartar emetic, purgatives, and occasionally digitalis in large doses, may (singly employed) all do good service in different instances which agree in respect of the causation and aspect of the delirium, though under this apparent similarity they mask real differences.

I might go on to mention many other maladies to which similar remarks would apply, but I will conclude this part of my subject by referring to an excellent clinical lecture by Dr. Sieveking (vide BRITISH MEdICAL Journal, Febriary 22, 1868), in which he maintains "that 
at one and the same time, we meet with cases of pneumonia that differ very materially in type, and therefore demand very varying treatment." He holds (and so do I) " that pneumonia varies very much in its intimate nature, although presenting physical signs that closely resemble one another in the different cases."

It will aid us to answer our question better if we think over, in a general way, the causes of disease. These are either material poisons originating external to the system, or developed within it, or traumatic influences, such as heat, cold, mental or bodily shock, etc., on the one hand, or simple decay or perversion of the natural forces of the body on the other. Fevers and inflammations are the main results of the operation of the former; degenerations, ulcers, and morbid growths as cancers, of the latter set of causes. In both, failure of vital power is essential to the occurrence of morbid action ; in the second group it is, or seems, to be almost everything; in the first, it permits the active cause to take effect. The existence of such a conservative power or energy, call it what we will, is a fact, and it is undeniable that it is much stronger in some persons than in others, and also in one organ or tissue, than in another, so that one part may suffer greatly from exposure to injury, and another much less. Moreover, it is matter of observation that where this resisting power is over-borne and disease set up, recovery ensues much more quickly in some persons than in others. In some, the perturbing influence is no sooner removed than the system springs back, as it were, at once to health ; in others, the return is slow, halting, and often incomplete. Now, this being so, even if we admit the causes of disease always to be the same, and to act with the same energy, which is more than doubtful, how can the results be constant. Must they not vary greatly in duration as well as in other respects?

The above considerations disincline me to believe that results of value will be obtained by observing the so-called natural course of disease left to itself. Where this is tolerably definite, it is sufficiently apparent as in the case of the exanthemata ; and where it is not readily discernible, I think the variations will be found so great that we can feel no certainty as to the course in individual instances.

The answer then, which I return to my question is, that diseases are perturbations of the normal functions, liable to vary so greatly in many important points that we need to be very careful in laying down rules for their treatment generically; that one instance of disease often resembles more truly another which bears a different name than it does one of the same designation; that the safest proceeding always is to consider the features of each individual case, to note what kind of morbid action predominates, and from what quarter peril is to be apprehended ; and that this caution is especially requisite when we apply the experience of one place or period to the diseases of another. Custom and convenience are, however, so strong, that I suppose to the end of the chapter we shall talk about the treatment of this disease or that, tacitly ignoring that which has been admitted again and again that, for the most part, they are inconstant and varying processes, and thereby often falling into error.

\section{CASE OF INSANITY DEPENDING ON SYPHILITIC INFECTION.}

By WILlIAM SMITH, EsQ., Surgeon, Clifton; Fellow of the Royal Medical and Chirurgical Society of England.

I THINK it admits of very little doubt that tubercular disease is frequently connected with insanity. Marsh miasm produces a peculiar mental depression; and, in pellagra, the mind and nervous system are frequently affected. In almost every form of blood-infection, there is more or less disturbance of the mental functions. It may be interesting to give a case in which I believe this was due to constitutional syphilis.

A young professional man was attacked with acute mania of several weeks' duration. The case was marked by febrile symptoms, active delirium, and tendency to violence. When this stage had passed over, the patient fell into a condition of profound melancholy and listlessness. It was at this period that the case came under my notice. There was apparently a settled determination not to speak. An answer in monosyllables might sometimes, indeed, be obtained with difficulty. There was certainly partial inability, and, with it, complete disinclination for any employment. He night be induced by great persuasiod to write a few lines to friends ; but, although tolerably well educated, in this condition he made many mistakes in most common matters. On one occasion, he repeated in his letter indelicate and offensive expressions. Although neither homicidal nor suicidal, he was sullen, and sometimes menacing in his looks and manners. The appetite and sleep were good, but the bowels were obstinately constipated. Various measures were employed, with very little, if any, success; and, at the end of three months, I began to fear my patient would pass into a condition of hopeless dementia. My attention was at this period called to a rash, principally on his chest and abdomen, but to some extent over the whole body. It was evidently syphilitic roseola; and with it were associated several large brown maculæ, the form which so often accompanies the squamous syphilide. I at once placed the patient under appropriate treatment. Iodide of potassium, gradually increased from five to ten grains, was given three times daily; and a mild mercurial was combined with it. In about a fortnight the symptoms were ameliorated; and at the end of a month he was so much improved as to con. verse rationally, although apparently with effort. Perfect recovery has resulted. The patient called on me a few days since. He denies having had syphilis, but pleads guilty to having suffered from "a simple chancre". This occurred about three months before the attack of insanity, and was treated empirically.

Griesenger, in his excellent work on mental diseases, says: "Constitutional syphilis does not readily lead to insanity otherwise than through palpable diseases of nutrition of the skull, of the brain, and of its membranes." This is, no doubt, true to a great extent; but I think that most medical men have seen cases in which there were no "palpable lesions", and yet mental deterioration, approaching, if not completely passing into, insanity, has been the result. Jackson, in his work on Syphilis of Internal Organs, acknowledges that, in cerebral syphilis, the brain-lesions are sometimes very slight; and, he adds, "some authors have failed to detect any." He says there is nothing peculiar in the symptoms of syphilitic cerebral disease.

From many cases in my own individual experience, I am inclined to believe that the blood-disease may and does produce a train of mental phenomena bearing no relation to any individual lesion. The converse is easily proved. All of us have seen cases of local syphilitic disease of the skull, brain and its membranes, with perfect integrity of the mental faculties.

\section{CLINICAL MEMORANDA.}

\section{BROW-AGUE CHANGED INTO AN AGUISH ATTACK UNDER THE ADMINISTRATION OF QUININE.}

\section{By Stanley L. Haynes, M.D., Medical Superintendent of Laver-} stock House Asylum, near Salisbury.

I BELIEVE the following case will be deemed interesting, from the conversion of hemicrania into an anomalous aguish attack.

F. H., aged 32, an attendant here, complained in February last of pain over the right eye and the anterior half of the temporal region, which was puffy to the sight and touch, and tender on pressure. This pain was continuous, but subject to exacerbations, especially at night, and was much increased by stooping, when giddiness and dimness of vision were added; it had been felt on waking a few mornings before, and was not preceded by any irregularity of health or accompanied by any other change. There was not any strabismus. He gave the following history. After enlisting in 1854, he went with his regiment to India in 1857 . In 1861 he was insensible during seven weeks in consequence of sun-stroke, and resultant "slight brain-fever." From 1862 to 1864 he suffered seven or eight times from "liver and fever" (by fever he means ague), some attacks lasting a month or so, and one having a duration of five months. He was treated with quinine, which arrested the attacks. They began always between 10 and II A.M., and ended between 3 and 4 P.M., sometimes later, leaving him unaffected for two or three days. In $186_{4}$, having served his full time, he claimed his discharge and returned; the sea-voyage caused his thorough convalescence. He continued quite well from that time until he complained to me. Suspecting, in the absence of all other ascertainable causes and of recognisable symptoms of impaired health, that his headache was a sequence of ague, I prescribed quinine in five-grain doses. The first was taken at 8 P.M. At 2 the following morning he awoke, feeling very ill, as if he were about to have an attack of ague, and with much nausea; he then found he had a distinct, well-marked sweating stage, which lasted from ten to fifteen minutes, and was succeeded by a rigor; this passed off in a very few minutes, leaving him free from browague, and feeling well. Notwithstanding this attack (he had not sent for me during it); he took a second dose at 6.30 A.M. ; this was, not succeeded by any disagreeable effects or apparent action. He is not conscious of having had any dry hot stage. Since the attack, he has been per. fectly well in every respect. The transposition of the cold and sweating stages, and their occurrence without the intervention of any dry stage, were remarkable. 